\title{
KANT E A ESTRATÉGIA METODOLÓGICA DA CRÍTICA DA RAZÃO PRÁTICA
}

\author{
Adriano Perin \\ PPGFIL - UFSC/CAPES
}

\begin{abstract}
The main point of disagreement about the heart of Kant's practical philosophy is whether it is guaranteed, within the Groundwork of Metaphysics of Morals and the Critique of Practical Reason, by a single argument holding two steps or by two distinct arguments. By favoring a methodological approach toward Kant's argumentation, this paper argues for the latter alternative. It is sustained that in the second Critique Kant structures his methodological strategy toward the justification of the practical use of reason in the context of the systematic discovery of the self-sufficiency of the practical and theoretical domains. Moreover, it is argued that this strategy is set forth by Kant in light of the reassuming of the systematic results not only of the Groundwork, but also of the Dialectic and the Canon of the Critique of Pure Reason. Therefore, the originality of the methodological strategy of the Critique of Practical Reason is considered in three moments: (i.) the presentation of a "critique" of the practical use assuring its self-sufficient validation; (ii.) the consideration of the idea of freedom as a systematic condition of admissibility; (iii.) the assignment of the "transmutability" between the moral law and the idea of freedom as the starting point for the accomplishment of the referred validation.
\end{abstract}

Key words: theoretical domain, practical domain, transition, freedom, moral law.

\section{Resumo}

O principal ponto de desacordo sobre o núcleo da proposta da filosofia prática kantiana é se essa proposta é garantida, na Fundamentação da metafísica dos costumes e na Crítica da razão prática, mediante um único argumento composto de dois passos ou mediante dois argumentos distintos. Primando por uma consideração metodológica da argumentação de Kant este trabalho defende a segunda alternativa. Sustenta-se que na segunda Crítica Kant estrutura a sua estratégia metodológica para justificação do uso prático no contexto da descoberta sistemática da auto-suficiência dos domínios teórico e prático da razão. 
Outrossim, defende-se que essa estratégia é conjecturada mediante a retomada dos resultados sistemáticos não só da Fundamentação, mas também da Dialética e do Cânone da Crítica da razão pura. A originalidade da estratégia metodológica da Crítica da razão prática é, então, considerada em três momentos: (i.) a apresentação de uma "critica" do uso prático que garanta a sua legitimação auto-suficiente; (ii.) a consideração da idéia de liberdade como uma condição sistemática de admissibilidade; (iii.) a designação da "transmutabilidade" da lei moral e da idéia de liberdade como o ponto de partida para a consecução da referida legitimação

Palavras-chave: domínio teórico, domínio prático, passagem, liberdade, lei moral.

\section{Introdução}

Na Dialética Transcendental da Crítica da razão pura e na terceira seção da Fundamentação da metafísica dos costumes Kant parece ter caracterizado o percurso metodológico da sua tentativa de legitimação do uso prático como a busca de uma passagem partindo do domínio teórico. Nesses textos, a idéia transcendental da liberdade é o "elemento chave" ao qual Kant confia a possibilidade de um "movimento dinâmico" do domínio teórico ao domínio prático. Desse modo, ele procura legitimar a partir da idéia teórica da liberdade um conceito prático da mesma ou, ainda, uma legislação prática enquanto sintética a priori. (Cf. KrV, A 329/B 386; GMS, BA 100). Uma consideração atenta da argumentação da Doutrina do Método da primeira Crítica parece mostrar, outrossim, que neste texto Kant adota uma tática metodológica bem diferente. Assim sendo, ele parece ali propriamente partir de um conceito prático de liberdade que, para a sua efetividade, não requer que se tome a idéia de liberdade como um ponto de partida. Quer dizer, a liberdade prática pode ser evidenciada ou conhecida pela experiência mediante a constatação da possibilidade de se admitir que a causalidade da natureza não é a única a determinar os eventos no mundo sensível. (Cf. $\mathrm{KrV}$, A 802/B830 - A803/B831).

O que Kant tem por certo na Crítica da razão prática ao conjecturar uma estratégia metodológica para a justificação do uso prático da razão é que a mesma não mais pode ser empreendida mediante uma passagem entre os domínios teórico e prático. Destarte, tanto a proposta, bem como o desdobramento e, ainda, o resultado da argumentação dessa obra sustentam 
precisamente a necessidade de que no próprio domínio prático seja legitimada uma legislação prática incondicionada e, também, que as conseqüências constitutivas desse empreendimento de legitimação tenham sua validade restrita ao âmbito intrínseco ao mesmo domínio.

Não obstante essa consideração, cabe ter presente que Kant apenas concebe a estratégia metodológica da Critica da razão prática partindo dos resultados da sua argumentação precedente que são sistematicamente favoráveis à sua consecução. Ou seja, o projeto da Crítica da razão prática de um estabelecimento auto-suficiente do uso prático da razão só poderia ser metodologicamente realizado se tomados em conta também os resultados sistemáticos que configuraram a busca de sua legitimação na Doutrina do Método, na Dialética Transcendental da primeira Crítica e na terceira seção da Fundamentação.

Aliás, vale dizer que tal estabelecimento auto-suficiente consiste propriamente na integração sistemática desses resultados. Em concordância com a Doutrina do Método da primeira Crítica, a justificação do uso prático da razão deveria ser dada de modo não-dependente em relação ao uso teórico. Levando em conta a Dialética Transcendental, a mesma justificação, se nãodependente em relação ao uso teórico, não seria também tomada como independente em relação aos resultados garantidos por aquele uso. Quer dizer, a possibilidade da idéia transcendental da liberdade em relação à causalidade da natureza seria precisamente o elemento que garantiria também a admissibilidade sistemática de um domínio prático autonomamente fundamentado. Por fim, a "transmutabilidade" da idéia teórica da liberdade e da legislação própria da razão no uso prático, resultado da argumentação na terceira seção da Fundamentação, seria o "impulso" principal para a realização de uma "Crítica" que deveria "garimpar" o contento próprio do domínio deste uso no intuito de garantir aquela legislação prática como legítima.

Neste trabalho considera-se a estratégia metodológica que Kant concebe na Crítica da razão prática como seminal para a justificação do uso prático da razão em três momentos. Argumentar-se-á que a percepção da necessidade de que essa justificação seja dada de modo auto-suficiente no domínio prático ao mesmo tempo em que confere originalidade à referida estratégia também parte precisamente da consideração dos resultados sistemáticos garantidos por Kant nas investigações precedentes. Então, será pertinente considerar: (i.) a especificidade da estratégia metodológica no domínio prático da razão que deve ser dada considerando o instrumentário 
próprio do mesmo; (ii.) a necessidade de que essa estratégia parta da admissibilidade da idéia transcendental da liberdade assegurada pelo uso teórico especulativo da razão; e, ainda, (iii.) a consecução sistemática da mesma estratégia, tendo presente a "transmutabilidade" dessa idéia teórica da liberdade e da lei moral.

\section{A "Crítica" do uso prático da razão e a necessidade de uma legitimação auto-suficiente no domínio prático}

Na Doutrina do Método da primeira Crítica, conforme já referido, Kant já parecia "desconfiar" que o uso prático da razão deve ser legitimado sem que para isso seja necessária uma passagem a partir do uso teórico. ${ }^{1}$ Contudo, essa "suspeita" seria mantida enquanto tal na Crítica da razão pura porque Kant ainda não possuía o instrumentário suficiente para garantir a sua devida consolidação. Ora, na estratégia metodológica da Crítica da razão prática Kant retoma precisamente esse pressuposto.

A apresentação da especificidade da estratégia metodológica da segunda Crítica, visando compreender como nessa obra a necessidade de uma legitimação do uso prático com um instrumentário configura a autosuficiência dos domínios teórico e prático, requer que se considere o sentido no qual Kant propriamente concebe a possibilidade de uma "Crítica" do uso prático da razão. Para tal, será brevemente feita uma comparação com o sentido no qual Kant apresenta uma "Crítica" do uso teórico da razão.

Já na Crítica da razão pura Kant assegura que uma "Crítica” deve ser entendida como "[...] um convite à razão para assumir a mais difícil das suas tarefas [Geschäfte], a saber, o conhecimento de si mesma e o estabelecimento de um tribunal que lhe assegure as pretensões legítimas e que, por outro lado, possa despachar todas as presunções infundadas". ${ }^{2}$ Nesse trecho Kant fornece a direção sistemática que toda a argumentação do sistema crítico-transcendental deve seguir: a apresentação dos elementos que na própria razão garantem uma fundamentação para o uso teórico bem como para o uso prático deve, imprescindivelmente, ser dada considerando a garantia das suas "preten-

\footnotetext{
1 Para a defesa da tese de que na argumentação do capítulo do "Cânone da razão pura" Kant parte do pressuposto de uma legitimação não-dependente do uso prático em relação ao uso teórico veja-se PERIN, Adriano. The canon of pure reason: Kant on the non-dependent establishment of the practical use and the unity of reason. Ethic@, v. 7, p. 137-150, 2008.

${ }^{2} \mathrm{KrV}, \mathrm{A}$ IX. Tradução própria.
} 
sões legítimas" e, também, o abandono das suas "presunções infundadas".

É também na primeira Crítica que Kant especifica o sentido em que a referida "Crítica" é empreendida com relação ao uso teórico. Assim, no início da Doutrina do Método encontra-se a argumentação de que

“[t]orna-se desnecessária uma Crítica da razão pura em seu uso empírico, pois os seus princípios são submetidos a um teste contínuo na pedra de toque da experiência; essa crítica também é dispensável na matemática, onde os seus conceitos têm que ser imediatamente apresentados in concreto na intuição pura, ficando desse modo patente em seguida qualquer coisa infundada e arbitrária nos mesmos. Onde, porém, nem a intuição empírica nem a intuição pura mantêm a razão em trilhos visíveis, a saber, em seu uso transcendental segundo meros conceitos, ela tanto necessita [da bedarf sie so sehr] de uma disciplina que detenha [abhalte] a sua tendência de estender-se para além dos estreitos limites da experiência possível, mantendo-a afastada de extravagância e do erro, que também toda a filosofia da razão pura [teórica] se ocupa unicamente dessa finalidade negativa. ${ }^{3}$,

Ora, se uso teórico uma "Crítica" objetiva estabelecer que para que a razão se assegure das condições de possibilidade do conhecimento em sentido estrito é imprescindível "dete[r] a sua tendência de estender-se para além dos estreitos limites da experiência possível”; no uso prático, Kant argumenta que uma "Crítica" "[...] tem a obrigação de deter [abzuhalten] a presunção da razão empiricamente condicionada de querer, ela só e exclusivamente, fornecer o fundamento determinante da vontade". ${ }^{4}$

Ao passo que no uso teórico era um uso constitutivo da razão "além" dos limites da experiência que era tido como transcendente, ou ainda, como dotado de "presunções infundadas"; agora, no uso prático, "[é] o uso empiricamente condicionado, que se arroga ao domínio absoluto, [que] é, ao contrário, transcendente e manifesta-se em pretensões e mandamentos que excedem totalmente o seu domínio". ${ }^{5}$ Kant nota que a possibilidade de se

\footnotetext{
${ }^{3}$ KrV, B 739. Rohden e Moosburger não mantêm o itálico do texto original em "so sehr" e traduzem "abhalten" por "domar".

${ }^{4} \mathrm{KpV}, \mathrm{A} 31$.

${ }^{5} \mathrm{KpV}, \mathrm{A} 31$.
} 
apresentar, mediante uma "Crítica", um uso puro da razão no domínio prático deve justificar, do mesmo modo que no domínio teórico, esse uso prático como "unicamente imanente". Todavia, ele assegura que tal justificativa deve ser empreendida de um modo que "[...] consiste precisamente na relação inversa do que podia ter sido dito sobre a razão pura no uso [teórico] especulativo". ${ }^{6}$

Kant dedica quase toda a argumentação do Prefácio e da Introdução da Crítica da razão prática à explicação da referida "relação inversa", que agora possibilita a ele a realização de uma "Crítica" da razão também no domínio prático com uma estratégia metodológica própria.

Assim, já nas primeiras palavras da obra ele considera necessário “[...] esclare[cer] suficientemente porque [a mesma] Crítica não é intitulada Crítica da razão pura prática e sim Crítica razão prática em geral". ${ }^{7}$ Que a "Crítica" seja denominada Crítica da razão prática se deve, segundo Kant, ao fato de que, ao procurar instituir um uso prático como legítimo, ela "[...] não precisa criticar a própria faculdade pura para ver se razão não se excede, com uma tal faculdade pura, numa vã presunção (como certamente ocorre com a razão [teórica] especulativa)" ${ }^{8}$

De modo diferente, a possibilidade de instituir um uso prático como legítimo é vista mediante uma "Crítica" do uso empiricamente condicionado da razão. Assim, Kant argumenta que, ao passo que "[o] uso teórico da razão ocupava-se com objetos da simples faculdade de conhecer, e uma crítica da mesma com vistas a este uso concernia propriamente só à faculdade de conhecer pura, porque esta provocava a suspeita, que depois também se confirmava, de que ela facilmente se perde, acima de seus limites, entre objetos inalcançáveis ou entre conceitos reciprocamente discordantes”; no uso prático a "[...] razão ocupa-se com fundamentos determinantes da vontade", sendo que para uma "Crítica" do mesmo uso "[...] a questão

\footnotetext{
${ }^{6} \mathrm{KpV}, \mathrm{A}$ 31. Sobre esse ponto vale considerar HENRICH, Dieter. Ethics of autonomy. In: The unity of reason: essays on Kan's philosophy. Trad. Richard Velkley. London: Harvard University Press, 1994. p. 93. Henrich afirma que "[e]nquanto que a Crítica da razão pura limita a possibilidade do conhecimento à experiência e é, então, dirigida contra um uso da razão apenas com base em si mesma, a crítica na sua forma prática é dirigida precisamente contra o seu uso empiricamente condicionado. Os títulos dos dois trabalhos devem, então, ser lidos não simplesmente como análogos mas sim como opostos em sentido. Tanto a razão pura teórica como a razão prática condicionada empiricamente fazem afirmações injustificadas e demandam criticismo".

${ }^{7} \mathrm{KpV}, \mathrm{A}$ 3. Rohden traduz a expressão "reine praktische Vernunft" por "razão prática pura". Neste e também nos próximos trechos citados a mesma expressão será traduzida por "razão pura prática".

${ }^{8} \mathrm{KpV}, \mathrm{A} 3$.
} 
primeira é se a razão pura basta por si só para a determinação da vontade ou se somente enquanto razão empiricamente condicionada ela pode ser um fundamento determinante da mesma". ${ }^{9}$

$\mathrm{Na}$ Crítica da razão prática Kant empreende esta última tarefa tanto mostrando que a razão pura possui para a "determinação incondicional da vontade" uma legislação prática que a razão empiricamente condicionada não pode fornecer como mostrando que essa legislação é legítima desde que justiçada enquanto sintética a priori. Assim, a "Crítica" objetiva suprimir as "presunções infundadas" e transcendentes do uso empiricamente condicionado da razão no domínio prático e instituir um uso puro prático como imanente e concorde com as suas "pretensões legítimas" mediante a consideração de que essa legislação é sistematicamente possível em relação ao domínio teórico da razão e, ainda, necessária desde que dotada de um caráter sintético priori.

$\mathrm{Na}$ estratégia metodológica da segunda Crítica a admissibilidade de uma determinação incondicional da vontade e a garantia da sua necessidade são, respectivamente, consignadas a partir da consideração de que aquela admissibilidade é sistematicamente assegurada pela idéia teórica da liberdade e, também - tendo presente a impossibilidade de se tomar a mesma idéia como um primeiro princípio - justificada no seu caráter sintético a priori de modo auto-suficiente. Nos próximos dois momentos considera-se, então, como Kant concebe a estratégia metodológica da Critica da razão prática de

${ }^{9}$ Trechos citados em KpV, A 30. Aqui também é pertinente considerar HENRICH, Dieter. The deduction of the moral law: the reasons for the obscurity of the final section of Kant's Groundwork of the metaphysics of morals. In: GUYER, Paul (Ed.). Groundwork of the metaphysics of morals: critical essays. Oxford: Rowman \& Littlefield, 1998. p. 309. Henrich assegura que "[a]penas aquela razão prática que não é pura, mas todavia pressupõe interesses sensivelmente condicionados para toda ação precisa ser criticada: isso porque ela desenvolve a opinião de que todas as motivações são como que propriamente suas, e essa 'pressuposição' é que será repelida. Num programa fundamentado desse modo, 'criticar' significa apenas disputar ou rejeitar. O sentido mais teórico de 'crítica', de acordo com o qual a crítica pertence à razão enquanto tal e, assim, a um todo de realizações, não pode mais ser considerado quando a meta tem se tornado uma crítica da 'razão empiricamente condicionada'". Considera-se ainda HENRICH, Dieter. Ethics of autonomy. In: The unity of reason: essays on Kant's philosophy. Trad. Richard Velkley. London: Harvard University Press, 1994. p. 93. Neste trabalho Henrich também sustenta que "[...] o problema genuíno de uma Crítica da razão prática encontra-se na questão de qual 0 modo em que a razão é prática. A razão pode ser prática em dois sentidos, como 'pura' e como 'empiricamente condicionada'. A razão prática empiricamente condicionada certamente desenvolve princípios para a prática, mas apenas com relação a móbiles para a ação que não tem o seu fundamento naqueles princípios mesmos. [...] Apenas uma razão prática que torna suficiente a determinação da vontade por si mesma com outros impulsos externos seria pura. É a tese de Kant de que uma tal razão realmente existe. Kant estabelece para a Crítica da razão prática a tarefa de refutar aqueles que pensam que a nossa razão pode ser prática apenas se ela é ao mesmo tempo empiricamente condicionada". 
modo a não prescindir dos resultados sistematicamente alcançados no domínio teórico mediante a idéia transcendental da liberdade e como essa estratégia garante agora um uso autonomamente fundamentado no domínio prático da razão.

\section{A idéia transcendental da liberdade e a admissibilidade sistemática da legitimação auto-suficiente do uso prático da razão}

No Prefácio da Segunda Edição da Crítica da razão pura Kant já assegura que "[...] um uso prático absolutamente necessário da razão (o moral) [...] não necessit[a] de nenhuma ajuda da razão [teórica] especulativa”. ${ }^{10}$ Essa afirmação contempla, já neste texto de 1787 , a convicção de que os domínios teórico e prático da razão devem ser legitimados de modo auto-suficiente. Não obstante a mesma convicção, Kant também tem como certo que uma legitimação auto-suficiente do uso prático não pode ser considerada de modo independente, ou ainda inconseqüente, em relação àquela legitimação do uso teórico já empreendida. Kant insiste, contudo, que a mesma legitimação só é possível desde que sistematicamente assegurada, embora não ainda edificada, pelo uso teórico. Assim, um pouco mais adiante no mesmo Prefácio, Kant chama a atenção para a necessidade de se

“[...] admiti[r] agora que a moral pressupõe necessariamente a liberdade (no sentido mais estrito) como propriedade da nossa vontade, na medida que na nossa razão encontram-se a priori como dados mesmos princípios práticos originários que, sem a pressuposição da liberdade, seriam absolutamente impossíveis; se, porém, a razão [teórica] especulativa tivesse demonstrado que essa liberdade era impensável, esta pressuposição, ou seja a moral, teria necessariamente que ceder à outra cujo contrário envolve uma manifesta contradição, e consequentemente a liberdade e com ela a moralidade (pois o seu oposto não contém nenhuma contradição se a liberdade já não for pressuposta) dar lugar ao mecanismo da natureza. Como para a moral nada mais necessito a não ser que a liberdade não se contradiga e portanto seja pelo menos pensável sem necessidade de discerni-la ulteriormente, que, portanto, não oponha nenhum

${ }^{10} \mathrm{KrV}, \mathrm{B} X X V$. 
obstáculo ao mecanismo natural precisamente da mesma ação (tomada em outra relação), assim tanto a doutrina da moralidade como a da natureza mantêm o seu lugar. 11 "

Nesse trecho fica claro que a pressuposição da idéia da liberdade figura como um elemento que sistematicamente legitima a possibilidade do uso prático da razão. É só essa "não-contraditoriedade" em relação à causalidade da natureza que a razão no uso prático sistematicamente exige agora do seu uso teórico especulativo. É nesse sentido que Kant também assegura que, "[c]om um tal procedimento, a razão [teórica] especulativa ainda assim nos conseguiu pelo menos lugar para tal ampliação [Erweiterung] [prática], embora tivesse que deixá-lo vazio, competindo-nos preenchê-lo, se pudermos, com os dados práticos, ao que por ela somos até mesmo convidados". ${ }^{12}$

De fato, o uso teórico parece "convidar" a um preenchimento daquele lugar vazio que ele encontra diante de si precisamente porque o mesmo lugar se apresenta a ele sempre como necessariamente indeterminado teoricamente, ou seja, como um campo no qual ele não pode jamais exercer um uso constitutivo. O que em 1787 no texto do Prefácio da Segunda Edição da Crítica parece ser muito claro para Kant é que esse "convite" do uso teórico é assinalado pela impossibilidade de qualquer ajuda sua para o uso prático naquele "preenchimento". O uso teórico pode, isso sim, garantir que o uso prático tem legitimidade sistemática num tal empreendimento.

$\mathrm{Na}$ Crítica da razão prática Kant analisa pelo menos em dois conhecidos momentos a necessidade de se pressupor a idéia transcendental da liberdade como uma condição da admissibilidade sistemática - embora não como uma condição de legitimação - do uso prático da razão. Assim, é necessário considerar o sentido em que a argumentação que apresenta a liberdade como "ratio essendi" e como "credencial" da lei moral deve ser compreendida. Vale considerar os referidos momentos:

“[i.] Para que não se imagine encontrar aqui inconseqüências, quando agora denomino a liberdade condição da lei moral e depois, no tratado, afirmo que a lei moral seja a condição sob

${ }^{11} \mathrm{KrV}$, B XXVIII/XXIX. O trecho segue a tradução de Rohden e Moosburger, mas apresenta algumas alterações feitas mediante a consideração do texto original.

12 KrV, B XXI. Tradução modificada. 
a qual primeiramente podemos tornar-nos conscientes da liberdade quero apenas lembrar que a liberdade é sem dúvida a ratio essendi da lei moral, mas que a lei moral é a ratio cognoscendi da liberdade. Pois, se a lei moral não fosse pensada antes claramente em nossa razão, jamais nos consideraríamos autorizados a admitir algo como a liberdade (ainda que esta não se contradiga). Mas, se não existisse liberdade alguma, a lei moral não seria de modo algum encontrável em nós. ${ }^{13}$

[ii.] De fato a lei moral é uma lei de causalidade mediante liberdade e, portanto, da possibilidade de uma natureza suprasensível, assim como a lei metafísica dos eventos no mundo sensorial era uma lei da causalidade da natureza sensível; logo aquela determina aquilo que a filosofia especulativa tinha que deixar indeterminado, a saber, a lei para uma causalidade cujo conceito na última era só negativo e, portanto, proporciona a este, pela primeira vez, realidade objetiva."

Esta espécie de credencial [Art von Kreditiv] da lei moral [...] é, em vez de toda a justificação a priori, plenamente suficiente à suplementação de uma necessidade [Bedürfnisses] da liberdade. ${ }^{14}$

\footnotetext{
${ }^{13} \mathrm{KpV}$, nota em A 6. Negritos adicionados.

${ }^{14} \mathrm{KpV}, \mathrm{A}$ 82/83. Negritos adicionados. Rohden traduz "Bedürfniss" por "carência". Que na segunda Crítica a idéia transcendental da liberdade é tomada por Kant como uma condição de admissibilidade sistemática, mas não como uma condição de legitimação, do uso prático da razão também deve ser considerado nos seguintes trechos:

i. KpV, A 4: "Mas a liberdade é também a única entre todas as idéias da razão especulativa de cuja possibilidade sabemos [wissen] a priori, sem, contudo compreendê-la [ohne sie doch einzusehen], porque ela é a condição da lei moral que sabemos [wissen]";

ii. KpV, A 13: "O conceito de liberdade é a pedra de escândalo para todos os empiristas mas também a chave das mais sublimes proposições fundamentais práticas para os moralistas críticos";

iii. KpV, A 32: "A lei da causalidade a partir da liberdade, isto é, qualquer proposição fundamental prática, constitui aqui inevitavelmente o começo e determina os objetos aos quais esta proposição unicamente pode ser referida";

iv. KpV, A 76: "Logo, essa lei [a lei moral] tem que ser a idéia de uma natureza, não dada empiricamente e, contudo, possível pela liberdade, por conseguinte de uma natureza supra-sensível à qual conferimos realidade objetiva pelo menos numa perspectiva prática";

v. Br, AA 11: 155: "A possibilidade da liberdade, se essa é considerada (como na Crítica da razão pura) antes de qualquer discussão da lei moral, significa apenas o conceito transcendental de causalidade de uma criatura terrena em geral desde que aquela causalidade não é determinada por nenhum fundamento no mundo sensível; e tudo o que é mostrado é que não há nada auto-contraditório sobre esse conceito".
} 
De momento é pertinente considerar apenas as afirmações em destaque, sendo que os demais pontos da argumentação serão tratados na última parte do trabalho. Vale aqui considerar, então, que o resultado sistemático acerca da idéia transcendental da liberdade, que fora assegurado na Dialética Transcendental, é plenamente mantido na segunda Crítica e, mais ainda, tomado como um ponto no qual fica assegurada a admissibilidade sistemática da estratégia metodológica da mesma obra de uma legitimação auto-suficiente do uso prático.

Assim, ao assegurar que a liberdade é a "condição", a "ratio essendi" ou a "credential" da lei moral, Kant tem plena convicção de que o uso teórico especulativo já garante, ao admitir esse conceito, a possibilidade sistemática para um uso prático da razão. $O$ que ele não pode garantir, contudo - e que a Crítica da razão prática procura propriamente mostrar - é que essa possibilidade seja uma condição suficiente de legitimação. Então, em relação à retomada e também à importância do resultado sistemático da Dialética Transcendental da primeira Crítica para a estratégia metodológica da segunda Crítica, é proeminente ter presente que, se o uso teórico especulativo mediante a idéia transcendental da liberdade configura sistematicamente a possibilidade da mesma estratégia, ele também conserva o lugar necessário para a sua realização sem o emprego constitutivo de qualquer elemento do domínio teórico, ou seja, como um "lugar vazio".

A consideração da liberdade transcendental como uma condição de possibilidade, mas não como um primeiro princípio ou uma condição de legitimação, parece estar marcada por outro resultado sistemático que sinaliza de modo peculiar a estratégia metodológica da segunda Crítica. Seria a "transmutabilidade" dessa idéia teórica e da legislação prática da razão, que exige uma legitimação enquanto sintética a priori, que propriamente levaria à descoberta e à consecução de um projeto que procura instituir a mesma legitimação de modo auto-suficiente. Essa "descoberta” da Fundamentação parece ser, assim, não apenas um resultado sistemático, mas também o elemento apenas a partir do qual se pode compreender o modo em que o uso

Negritos adicionados em todos os trechos. No trecho "i." Rohden traduz o verbo "wissen" no segundo momento em que ele é usado por "conhecemos" e "ohne sie doch einzusehen" por "ter perspiciência dela". Nesse e nos demais trechos citados "einsehen/Einsicht" são traduzidos por "compreender/compreensão". 
prático da razão pode e deve agora ser legitimado mediante uma estratégia metodológica intrínseca ao seu domínio próprio.

\section{A "transmutabilidade" da idéia teórica e da legislação prática e a consecução sistemática da estratégia metodológica da Crítica da razão prática}

A estratégia metodológica acatada como única passível de garantir o caráter sintético a priori de uma legislação incondicionada de modo autosuficiente no domínio prático e apresentada nesta parte do trabalho mediante a consideração de dois pontos da argumentação de Kant: (i.) as possibilidades sistemáticas disponíveis à legitimação de uma proposição fundamental prática dotada de caráter sintético a priori e (ii.) a retomada da "transmutabilidade" da mesma proposição fundamental e da idéia da liberdade.

\section{i. As possibilidades sistemáticas disponíveis à estratégia metodológica da Crítica da razão prática}

Já na Fundamentação Kant argumenta que uma legislação prática, desde que incondicionalmente determinante da vontade e, assim, válida para seres racionais em geral, pode unicamente ser concebida como autonomia da vontade, ou seja, como "[...] aquela sua propriedade graças à qual ela é para si mesma a sua lei (independentemente da natureza dos objetos do querer)". ${ }^{15}$ Essa caracterização objetiva da legislação prática é, segundo Kant, totalmente suficiente para que ela seja "fixada" como a única forma possível de uma determinação incondicional da vontade. Kant mostra, outrossim, que essa legislação concebida como possível mediante um método analítico pode também ser pressuposta como sintética a priori. Contudo, o que ainda não pode ser garantido mediante uma argumentação analítica é que a mesma legislação prática seja de fato "estabelecida" como sintética a priori, ou seja, que determine incondicionalmente a vontade de todo ser racional e, assim, também de seres racionais sensíveis.

Para ilustrar a natureza da estratégia metodológica da segunda Crítica para dar conta dessa tarefa pode-se fazer uma breve comparação com a tarefa que Kant se dispõe a realizar na dedução das categorias. Sem a intenção de fazer uma análise exaustiva e pretensiosa, objetiva-se, mediante a mesma

15 GMS, BA 88. 
comparação, unicamente mostrar que, no domínio prático, deve-se considerar uma possibilidade que não pode ser dada à razão no domínio teórico. Essa possibilidade sistemática consiste no fato de que no domínio prático a razão pode partir da lei moral como uma proposição sintética a priori para estabelecer a sua legitimidade. No uso teórico, por outro lado, uma proposição sintética a priori não pode ser tomada como ponto de partida, sendo que ela é o próprio resultado de um procedimento de legitimação do mesmo uso que se configura na determinação de intuições por conceitos puros.

A possibilidade de a lei moral ser fundamentalmente tomada como uma proposição sintética a priori ou, em outras palavras, ser considerada enquanto tal como ponto de partida da sua própria legitimação, deve ser vista como um elemento essencial na compreensão da estratégia metodológica segundo a qual Kant concebe tal legitimação.

$\mathrm{Na}$ dedução das categorias, empreendimento que visara a fundamentação incontestável do uso teórico da razão, Kant garantira que esses conceitos têm a sua validade objetiva assegurada a priori no entendimento sem referência a intuições da sensibilidade ou a intuições empíricas. Do mesmo modo pode-se dizer, agora no domínio prático, que uma legislação prática incondicionada é válida objetivamente sem referência a qualquer outra condição que não seja a própria forma da sua legalidade. Kant dedica as duas primeiras seções da Fundamentação e também boa parte da argumentação dos oito primeiros parágrafos da segunda Crítica à especificação da validade objetiva da lei moral. Ela é garantida, segundo a argumentação desses textos, objetivamente num nível de seres racionais em geral.

Todavia, assim como o núcleo da dedução das categorias consistira no percurso sintético dos conceitos puros do entendimento objetivamente válidos à legitimação do seu uso enquanto referidos a intuições, no domínio prático, também se apresenta como tarefa seminal a garantia de que a legislação objetiva da lei moral seja assegurada sinteticamente como válida também para seres que não são unicamente racionais, ou seja, seres também sensíveis. Em uma palavra, Kant estrutura o percurso sintético no domínio do uso prático da razão com a garantia de que aquela legislação objetivamente "fixada" agora é "estabelecida" como uma legislação incondicional também para seres que, por sua própria natureza, não corroboram uma determinação garantida pela lei na sua caracterização objetiva.

O próprio Kant, ao assegurar que a lei moral apresenta-se a seres racionais sensíveis como um imperativo categórico, faz menção à 
comparação aqui proposta. Considera-se o trecho onde Kant justifica porque a lei moral constitui-se como uma proposição sintética a priori:

"E esse dever categórico representa uma proposição sintética a priori, justamente pelo fato de que [dadurch] acima da minha vontade afetada por apetites sensíveis sobrevém ainda a idéia dessa mesma vontade, mas como pertencente ao mundo inteligível, pura, prática por si mesma, que contém a condição suprema da primeira, segundo a razão; é semelhante ao modo que os conceitos do entendimento, os quais em si mesmos nada significam a não ser a forma da lei em geral, são adicionados às intuições do mundo sensível e, então, tornam possíveis proposições sintéticas a priori sobre as quais repousa todo o conhecimento da natureza. ${ }^{16 \text { " }}$

A "semelhança" sugerida por Kant entre proposições sintéticas a priori no domínio teórico e no domínio prático não deve ser compreendida além da necessidade que se apresenta em ambos esses domínios de um movimento sintético para a garantia das mesmas proposições como legítimas. Conforme já dito, no domínio teórico o mesmo movimento se configura a partir de conceitos tidos como objetivamente válidos a intuições sensíveis e, no domínio prático, a partir de uma legislação incondicional objetiva referida a uma vontade pura à sua legitimação como válida igualmente para uma vontade que também é sensivelmente condicionada. ${ }^{17} \mathrm{O}$ que deve ser considerado é que, neste último caso, pode-se partir de uma proposição fundamental como sintética num empreendimento que visa a sua própria legitimação enquanto tal.

Na segunda Crítica, Kant precisamente nota que, no domínio prático, "[a] lei de causalidade a partir da liberdade, isto é, qualquer proposição fundamental pura prática, constitui aqui inevitavelmente o começo e

${ }^{16}$ GMS, BA 112. Paulo Quintela traduz "dadurch" por "porque". Tradução própria da última frase.

${ }_{17}$ Assim também é necessário compreender o trecho da Crítica da razão prática onde Kant afirma que "[p]odemos tornar-nos conscientes de leis práticas puras do mesmo modo como somos conscientes de proposições fundamentais teóricas puras, na medida em que prestamos atenção à necessidade com que a razão as prescreve a nós e à eliminação de todas as condições empíricas, à qual aquela nos remete". KpV, A 53. A semelhança se dá apenas na necessidade de um procedimento de legitimação, tanto no domínio teórico como no domínio prático, de proposições sintéticas a priori para a própria garantia de um uso legítimo da razão em ambos esses domínios. Contudo, há de se considerar, conforme argumentado no que procede, que no domínio prático essa legitimação é compreendida de um modo necessariamente diferente do modo em que ela é empreendida no domínio teórico. 
determina os objetos aos quais esta proposição unicamente pode ser referida”. ${ }^{18}$ O que é necessário compreender nessa citação, e também na estratégia metodológica da segunda Crítica enquanto tal, é que a legitimação do uso prático deve partir da proposição fundamental que se garante no domínio desse uso como objetivamente válida num nível de seres racionais em geral e também como sintética a priori na medida em que esta validade é pensada como válida para seres que são também sensíveis. É propriamente esse último ponto, ou seja, a validade de uma legislação incondicional prática para seres também sensíveis que justifica a insistência de Kant de que uma "Crítica" do uso prático da razão tem em vista o uso empiricamente condicionado da razão. Em outras palavras, é necessário mostrar que esse uso empiricamente condicionado não constitui o único fundamento determinante da vontade de seres que são também empiricamente condicionados.

Kant recorda que no domínio teórico a "Crítica" conseguiu garantir que:

"[p]roposições fundamentais sintéticas a partir de simples conceitos e sem intuições eram impossíveis, muito antes, só podiam ocorrer em referência àquela intuição que era sensível, por conseguinte também só em referência a objetos da experiência possível, porque unicamente os conceitos do entendimento vinculados a essa intuição tornam possível aquele conhecimento que chamamos experiência. ${ }^{19}$ "

No domínio prático, por sua vez, Kant agora assegura que a "Crítica" "[...] pode sem objeção começar, e tem que fazê-lo, a partir de leis práticas puras e de sua efetividade. Mas, em vez da intuição, põe-lhes como fundamento o conceito de sua existência no mundo inteligível, ou seja, da liberdade". 20

\footnotetext{
$18 \mathrm{KpV}, \mathrm{A} 32$.

$19 \mathrm{KpV}, \mathrm{A} 73$.

${ }^{20} \mathrm{KpV}$, A 79. Sobre esse ponto também vale considerar KpV, A 159/160: "A Analítica da razão teórica pura ocupava-se com o conhecimento dos objetos que possam ser dados ao entendimento, e tinha de começar pela intuição, por conseguinte (porque esta é sempre sensível) pela sensibilidade, e a partir daí pela primeira vez avançar até conceitos (dos objetos dessa intuição), e só após o tratamento de ambos era-Ihe permitido terminar nas proposições fundamentais. Contrariamente, [...] uma crítica da Analítica da razão pura prática, na medida em que esta deve ser uma razão prática (que é o problema propriamente dito), tem que começar da possibilidade de proposições fundamentais práticas a priori".
} 
Conforme a argumentação do momento anterior, o "fundamento" ao qual Kant se refere nesse ponto deve ser entendido apenas como uma condição sistemática de admissibilidade. A esse respeito, também uma formulação do final da terceira seção da Fundamentação, se não ainda antecipa, se mostra bem concorde com a estratégia metodológica da segunda. Assim, naquele texto Kant assegurava que:

"A pergunta, pois: - Como é possível um imperativo categórico? - pode ser respondida na medida em que se pode indicar o único pressuposto de que depende a sua possibilidade, quer dizer, a idéia da liberdade, e igualmente na medida em que se pode compreender [einsehen] a necessidade desse pressuposto, o que para o uso prático da razão, isto é, para a convicção da validade desse imperativo, e portanto também da lei moral, é suficiente; mas como seja possível este pressuposto mesmo, isso é o que nunca se deixará jamais compreender [einsehen] por nenhuma razão humana. ${ }^{21}$ "

E também no projeto da Fundamentação que Kant conclui que "[...] nós não compreendemos, na verdade, a necessidade prática incondicionada do imperativo moral, mas compreendemos, no entanto, a sua incompreensibilidade". 22

Ora, é esse "pressuposto" que não se deixa jamais compreender, ou a singular compreensão da incompreensibilidade de uma legislação prática dotada de caráter sintético a priori partindo do mesmo, que se deve ter presente na estratégia metodológica da Crítica da razão prática que visa dar conta da alegação de tal caráter.

\section{ii. a retomada da "transmutabilidade" da lei moral e da idéia da liberdade e a consecução da estratégia metodológica da Crítica da razão prática}

A perspectiva da qual parte propriamente a estratégia metodológica da Crítica da razão prática é precisamente a de que não se pode compreender ou

\footnotetext{
${ }^{21}$ GMS, BA 125. Paulo Quintela traduz "einsehen" por "aperceber".

22 GMS, BA 128. "Und so begreifen wir zwar nicht die praktische unbedingte Notwendigkeit des moralischen Imperativs, wir begreifen aber doch seine Unbegreiflichkeit".
} 
justificar a legislação prática da razão como sintética a priori partindo-se da idéia teórica da liberdade como uma condição de legitimação. ${ }^{23}$

Assim, antes mesmo de proporcionar ao leitor o núcleo dessa estratégia, Kant apresenta nos parágrafos cinco e seis da mesma obra, como duas tarefas inviáveis, tanto a trajetória da legislação prática à idéia da liberdade como a trajetória desta àquela legislação prática. ${ }^{24}$

Ora, a inviabilidade de se partir da idéia da liberdade com o intento de justificar a lei moral enquanto sintética a priori se deve, segundo Kant, ao fato de que "[...] nem podemos tornar-nos imediatamente conscientes dela, porque seu primeiro conceito é negativo, [e] nem podemos inferir-la da experiência, pois a experiência só nos dá conhecer as leis dos fenômenos, por conseguinte, o mecanismo da natureza, o exato oposto da liberdade". ${ }^{25}$ Assim sendo, o que se mostra evidente agora para Kant é que, visto que a idéia da liberdade, "[...] no que concerne a sua possibilidade, [é] uma proposição fundamental analítica da razão especulativa pura”, ${ }^{26}$ ou seja, ela não pode ser demonstrada como uma causalidade determinante no mundo sensível, ela também não pode garantir uma legislação sintética a priori, que se configura enquanto tal justamente porque deve ter um caráter determinante para seres que se caracterizam por possuírem uma natureza também sensível.

\footnotetext{
23 Que a "transmutabilidade" da idéia teórica da liberdade e a legislação prática, garantida já na argumentação da Fundamentação, é tomada como um elemento sistemático a partir do qual a estratégia da segunda Crítica é empreendida considera-se também nos seguintes trechos:

i. KpV, A 52: "[...] a liberdade e a lei prática incondicionada referem-se de modo transmutável [wechselsweise]". O termo "wechselsweise" é traduzido por Rohden por "reciprocamente";

ii. KpV, A 167/168: "[...] se se compreendesse [einsähe] a possibilidade da liberdade de uma causa eficiente, compreender-se-ia [einsehen würde] também talvez não apenas a possibilidade mas talvez a necessidade da lei moral enquanto lei prática suprema de entes racionais, aos quais se atribui liberdade da causalidade da sua vontade; pelo fato de que ambos os conceitos estão tão inseparavelmente vinculados";

iii. $\mathrm{Br}, \mathrm{AA}$ 11: 155. "O conceito de liberdade, como causalidade, é apreendido numa afirmação, e este conceito é sem circularidade transmutável com o conceito de um fundamento moral de determinação";

Sobre esse ponto vale considerar ALLISON, Henry. Kant's theory of freedom. New York: Cambridge University press, 1995. p. 201-213. Nesse trabalho Allison analisa, sob a denominação de "tese da reciprocidade", a correlação que Kant estabelece entre os conceitos da liberdade e da lei moral tanto na sua apresentação na terceira seção da Fundamentação como na sua retomada na segunda Crítica.

${ }^{24} \mathrm{KpV}, \mathrm{A}$ 51-52. Aqui também a tradução do título dos referidos parágrafos "Aufgabe I/ Aufgabe II" como "tarefa I/ tarefa II". Nesses dois parágrafos Kant mostra que a legislação prática incondicionada e a liberdade transcendental são conceitos que se equivalem, sendo que partindo-se ou pressupondo-se um deles chega-se imediata ou analiticamente ao outro. A exposição dessa analiticidade, que marca qualquer tentativa de movimento entre esses conceitos, parece justamente ter em vista a caracterização da impossibilidade de garantir de modo sintético a priori um dos conceitos partindo-se do outro.

${ }^{25} \mathrm{KpV}, \mathrm{A} 53$.

${ }^{26} \mathrm{KpV}, \mathrm{A} 84$.
} 
Abreviando os dois pontos tomados como guia da argumentação neste momento parcial, a saber, as possibilidades sistemáticas à justificação da lei moral e a "transmutabilidade" desta com a idéia da liberdade, pode-se dizer que o projeto da segunda Crítica parece estar num impasse: ao mesmo tempo em que a proposição da moralidade pode ser tomada fundamen-talmente como sintética a priori, a sua justificação não pode ser oferecida nem se partindo da idéia da liberdade e, muito menos ainda, a partir da experiência.

O que é também claro para Kant é que, tratando-se de uma justificação no sentido teórico, o referido impasse não é apenas aparente, mas precisamente intrínseco à natureza do problema que se tem presente. Assim sendo, se na Fundamentação fora dito que diante da explicação de uma legislação sintética a priori "toda a razão humana é absolutamente incapaz" ou que só se consegue compreender porque não é possível tal explicação; agora, na segunda Crítica, confirma-se também que "[...] toda a compreensão [Einsicht] humana termina tão logo tenhamos alcançado as forças ou faculdades fundamentais; pois sua possibilidade não pode ser concebida por nada, tão pouco pode ser também forjada e admitida arbitrariamente". ${ }^{27}$

De fato, Kant parece estar num problema que se situa propriamente no limite da investigação crítica. Isso porque uma explicação nesse sentido exigiria também que fosse dito como uma legislação concebida objetivamente mediante uma causalidade num mundo inteligível (ou mediante a liberdade) agora determina a vontade de seres também sensíveis. Mas, se no domínio teórico um movimento constitutivo no percurso sensível-inteligível fora comcebido como totalmente ilegítimo, agora, também no domínio prático, o movimento constitutivo no percurso inteligível-sensível não pode ser admitido.

Se considerada essa impossibilidade sistemática também se pode dizer que uma justificação no sentido teórico, sob a denominação de "dedução", não pode ser admitida por dois motivos:

i. Ela exigiria que fosse explicada sinteticamente em sentido teórico constitutivo uma relação que não pode ser abarcada por uma argumentação legítima nos moldes da filosofia crítica: como uma legislação concebida enquanto objetivamente válida num mundo inteligível determina necessaria-

${ }^{27} \mathrm{KpV}, \mathrm{A}$ 80. A esse respeito vale conferir também A 128: "[...] Pois o modo como uma lei pode ser por si e imediatamente fundamento determinante da vontade (o que com efeito é 0 essencial de toda a moralidade) é um problema insolúvel para a razão humana e idêntico à [questão]: como é possível uma vontade livre". 
mente uma vontade também sensivelmente condicionada;

ii. Mesmo que a referida explicação fosse concebida como legítima, ela não justificaria o caráter sintético a priori da lei moral. Isso porque, se excluída a possibilidade de se partir da idéia da liberdade e também de qualquer elemento do mundo sensível (como uma intuição), não resta nenhum outro elemento ao qual uma "dedução" poderia referir uma lei moral objetivamente válida a fim de justificá-la como sintética a priori.

E Kant precisamente assegura que:

"[...] a realidade objetiva da lei moral não pode ser provada por nenhuma dedução, por nenhum esforço da razão teórica, especulativa ou empiricamente apoiada, e, pois, ainda que se quisesse renunciar à certeza apodíctica, [nem] ser confirmada pela experiência e deste modo ser provada a posteriori e, contudo, é por si mesma certa. ${ }^{28}$ "

O que se garante até agora é que a proposição fundamental da moralidade pode ser presumida como sintética a priori, mas que qualquer explicação da mesma enquanto tal num sentido teórico e também empírico se mostra não apenas como impossível, mas também como desnecessária.

Contudo, vale aqui perguntar: que outra "saída" resta à estratégia metodológica da Crítica da razão prática? Na Fundamentação Kant já precavera que "[...] onde cessa a determinação segundo leis naturais, cessa também toda a explicação". ${ }^{29}$ Assim sendo, já nesse texto Kant acabara por concluir que para se pensar uma legislação como objetivamente válida num domínio que não é o teórico da legislação da natureza e, igualmente, para se justificar a mesma legislação como sintética a priori não se pode contar também com nenhum recurso de "explicação" no sentido teórico.

É também na Fundamentação que Kant assegurara que, não obstante vedado qualquer recurso teórico ou empírico, "[a]o introduzir-se assim pelo pensamento num mundo inteligível, a razão prática não ultrapassa em nada os seus limites". ${ }^{30}$ De fato, a própria argumentação dessa obra garantira que uma legislação no domínio prático da razão pode sistematicamente ser estabelecida como autonomia da vontade, mas que uma explicação de como

\footnotetext{
${ }^{28} \mathrm{KpV}, \mathrm{A}$ 81/82.

${ }^{29}$ GMS, BA 121.

30 GMS, BA 119.
} 
essa legislação objetiva determina a vontade de seres também subjetivamente condicionados transcenderia os próprios limites de legitimidade da razão. Conforme já dito, a segunda Crítica parte dessa determinação do "limite extremo de toda investigação moral”. Mas, agora Kant considera também que “[...] não é impossível pelo menos pensar uma lei - a qual serve meramente à forma subjetiva das proposições fundamentais - como fundamento determinante mediante a forma objetiva de uma lei em geral". ${ }^{31}$

Essa "mediação" entre os níveis objetivo e subjetivo agora se configura como imediata e totalmente intrínseca ao domínio prático da razão. Então, tendo presente a impossibilidade de realizar a mesma mediação com o apoio de qualquer recurso do domínio teórico e, também, com qualquer recurso empírico e, como conseqüência, a impossibilidade de entendê-la num sentido teórico constitutivo, Kant agora sugere a necessidade de que a mesma seja pensada no domínio prático considerando as condições sistemáticas disponíveis à razão no mesmo domínio.

A condição sistemática mais importante disponível à razão no domínio prático, como argumentado no início desta parte do trabalho, é que a própria argumentação analítica acerca de uma legislação objetiva incondicionalmente válida pode, sem contradição, já presumir essa legislação como sintética a priori. É justamente essa condição sistemática que Kant resgata na estratégia metodológica da Crítica da razão prática ao considerar que essa legislação deve ser ela mesma o elemento do qual se deve partir e unicamente ter em conta na sua própria justificação. Desse modo, a estratégia da segunda Crítica consiste essencialmente em determinar que é sistematicamente possível, e também para o domínio prático necessário, ter em conta apenas a própria possibilidade de que a lei moral objetivamente válida seja, sem recorrência a qualquer outro elemento, subjetivamente determinante.

$\mathrm{O}$ passo da argumentação da Fundamentação à argumentação da Crítica da razão prática, que caracteriza propriamente a estratégia metodológica desta última obra, é, então, de que, depois de se mostrar meticulosamente a impossibilidade de qualquer justificação no sentido teórico, a razão se vê sistematicamente dotada da possibilidade de admitir uma legislação prática como sintética a priori tendo a certeza de que nenhuma argumentação em tal sentido teórico pode negar a mesma e,

${ }^{31} \mathrm{KpV}, \mathrm{A} 55$. 
também, que, com essa admissibilidade, ela não apresenta uma "presunção infundada” ou um uso prático transcendente.

Então, na segunda Crítica Kant sustenta terminantemente que, embora sem o recurso a nenhuma justificativa de caráter teórico constitutivo, a razão não transcende os limites do seu domínio teórico e também não institui um uso num domínio prático transcendente ao admitir que aquela legislação objetiva determina categoricamente um ser também sensivelmente condicionado. Ou seja, essa admissibilidade, por si só e sem o recurso a qualquer outro elemento de justificação (ou explicação), é o único meio de garantir tanto a efetividade da tarefa específica concedida ao uso prático como as "pretensões legítimas" da razão em ambos os seus domínios.

Num conhecido trecho da segunda Crítica, e para o propósito deste trabalho suficiente, Kant expõe a referida admissibilidade da lei moral enquanto determinante da vontade de seres dotados de natureza também sensível:

"Pode-se denominar a consciência desta lei fundamental um factum da razão, porque não se pode sutilmente inferir-la de dados antecedentes da razão, por exemplo, da consciência da liberdade (porque esta consciência não nos é dada previamente), mas porque ela se impõe por si mesma a nós como uma proposição sintética a priori, que não é fundada sobre nenhuma intuição, seja pura ou empírica, se bem que ela seria analítica se pressupusesse a liberdade da vontade, para que porém se requereria como conceito positivo uma intuição intelectual, que aqui de modo algum se pode admitir. Contudo, para se considerar esta lei como inequivocamente dada, precisa-se observar que ela não é nenhum fato empírico mas o único factum da razão pura, que deste modo se proclama como originariamente legislativa (sic volo, sic jubeo). ${ }^{32}$ "

\footnotetext{
${ }^{32} \mathrm{KpV}, \mathrm{A}$ 56. Aqui não será possível discutir as diversas formulações nas quais Kant apresenta a lei moral no seu caráter sintético a priori na segunda Crítica como factum da razão. Para tal discussão vale considerar: ALLISON, Henry. Kant's theory of freedom. New York: Cambridge University press, 1995. p. 230-239; BECK, Lewis White. A commentary on Kant's Critique of practical reason. Chicago: University of Chicago Press, 1960. p. 164-175.
} 
Ora, o que fica essencialmente garantido mediante a estratégia metodológica da Crítica da razão prática é que a legislação prática da razão por si mesma se impõe como sintética a priori. A aparente estranheza com que essa estratégia figura no projeto da filosofia moral madura de Kant somente pode ser contrafeita a partir da compreensão das possibilidades sistemáticas, as quais Kant rigorosamente tem presente ao apresentar a mesma estratégia e, também, a partir da imprescindível necessidade, de que ele também não abre mão, de garantir que o uso prático da razão possui uma legislação incondicionalmente válida para todo ser racional. ${ }^{33}$

Desse modo, o que é importante destacar acerca da estratégia metodológica que Kant apresenta para a sua filosofia moral em 1788 no projeto da Crítica da razão prática é que ela parece ser a única possível para um problema que se apresenta no domínio prático da razão sem a possibilidade de recorrer a qualquer elemento de justificação do domínio onde unicamente é garantida justificação no sentido teórico constitutivo. Então, deve-se ter em conta também que essa estratégia de Kant não pode ser justificada e nem refutada por qualquer argumentação de caráter teórico ou dedutivo. A sua aceitação e compreensão se deve essencialmente a que no domínio prático a lei moral pode primordialmente ser tomada como uma legislação sintética a priori, e, ainda, que a sua admissibilidade enquanto tal e, então, enquanto determinante da vontade de seres também sensivelmente condicionados, é totalmente legítima no que concerne ao todo da arquitetônica transcendental.

\footnotetext{
${ }^{33}$ A este respeito considera-se, HENRICH, Dieter. The deduction of the moral law: the reasons for the obscurity of the final section of Kant's Groundwork of the metaphysics of morals. In: GUYER, Paul (Ed.). Groundwork of the metaphysics of morals: critical essays. Oxford: Rowman \& Littlefield, 1998. p. 309. Henrich afirma que "[...] foi propriamente a experiência de Kant com a Fundamentação que tornou possível para ele conceber a Crítica da razão prática na inequivocidade e simplicidade que distingue essa obra. Nela, toda a filosofia moral deve ser fundamentada no 'facto' da consciência da lei que torna válida a afirmação incondicional e inegável da determinação da vontade. Pode-se apenas defender esse facto, então interpretá-lo e localizá-lo no nexus de todos os empreendimentos da razão. Kant expressa com toda clareza que não há nenhuma possibilidade de explicar esse facto enquanto tal, ou seja, de assegurar a validade da lei partindo de premissas nas quais essa validade não é já considerada como aceita. Com certeza, as condições de possibilidade da validade dessa lei devem ser clarificadas. Mas, a sua validade não pode ser demonstrada nem a sua origem, que se encontra além de todo conhecimento racional, ser pode ser entendida. Nesse sentido, [...] Kant declara que nenhuma tentativa de dedução do facto tem qualquer perspectiva de sucesso".
} 


\section{Conclusão}

Não obstante a estratégia metodológica da Crítica da razão prática que toma o seu desfecho na consideração de que no domínio prático a lei moral se apresenta enquanto sintética a priori como o único factum da razão e que ela pode ser reconhecida enquanto tal por um ser também condicionado sensivelmente - ser de caráter peculiar justamente pela impossibilidade de qualquer justificação teórica, é necessário dizer que esse desfecho é visto por Kant como o único possível. E isso porque ele objetiva tanto garantir um uso prático como legítimo quanto "zelar" pela arquitetônica da filosofia crítica no seu todo. Em relação a este último cuidado pode-se, agora, referir os seguintes resultados como conclusão da validez da estratégia adotada por Kant:

(i.) Fica garantido o uso teórico da razão como imamente, visto Kant não pensar mais a legitimação do uso prático a partir do mesmo uso, e ao mesmo tempo, o uso prático é agora instituído como imanente, dado que este mostra que um uso empiricamente condicionado da razão, que objetiva ser o único fundamento determinante da vontade, é que se institui como transcendente;

(ii.) A tese já promulgada no domínio teórico de que entre os âmbitos sistematicamente admitidos como mundo sensível e mundo inteligível não se pode realizar nenhuma passagem no sentido teórico constitutivo é totalmente consentida no domínio prático. A admissibilidade da lei moral enquanto sintética a priori como o único factum da razão pura prática tem presente precisamente essa tese;

(iii.) Assim, também o âmbito do supra-sensível, caracterizado no domínio teórico como indeterminado, mantém-se, no domínio prático, totalmente como tal num sentido teórico. Destarte, se aquela indeterminabilidade fora essencial para propriamente se poder admitir sistematicamente um domínio prático, este também, ao se instituir de modo auto-suficiente, confirma plenamente a mesma indeterminabilidade no sentido teórico. Quer dizer: "Assim se torna compreensível por que em toda a faculdade da razão somente o domínio prático possa ser o que nos eleva acima do mundo sensível [Sinnenwelt] e proporcione conhecimentos de uma ordem e conexão supra-sensível, mas que precisamente por isso podem ser 
estendidos somente tão longe quanto exatamente é necessário ao ponto de vista prático puro" (KpV, A 190);

(iv.) Por fim, pode-se dizer que a compreensão do intelectual e do sensível como não redutíveis, que é admitida no domínio teórico, é também sistematicamente considerada no domínio prático. Então, do mesmo modo que no domínio teórico foram mantidas sensibilidade e entendimento como duas faculdades distintas, no domínio prático é também mais do que essencial que se garanta que a razão, ao legitimar uma legislação incondicionada para a vontade de um ser também sensivelmente condicionado, não se "mescla" ou se reduz à esfera sensível. 


\section{Referências Bibliográficas}

ALLISON, H. Kant's theory of freedom. New York: Cambridge University press, 1995.

BECK, L. W. A commentary on Kant's critique of practical reason. Chicago: University of Chicago Press, 1960.

HENRICH, D. Ethics of autonomy. In: The unity of reason: essays on Kant's philosophy. Trad. Richard Velkley. London: Harvard University Press, 1994.

. The deduction of the moral law: the reasons for the obscurity of the final section of Kant's Groundwork of the metaphysics of morals. In: GUYER, Paul (Ed.). Groundwork of the metaphysics of morals: critical essays. Oxford: Rowman \& Littlefield, 1998. p. 303-341.

KANT, I. Kritik der reinen Vernunft (KrV). Hrsg. von Raymund Schmidt. Hamburg: Felix Meiner, 1993 (Philos. Bibliothek Bd. 37 a). Tradução de Valério Rohden e Udo Baldur Moosburger. São Paulo: Abril Cultural, 1991.

. Grundlegung zur Metaphysik der Sitten (GMS). In: Akademie Textausgabe, Bd. VII, Berlin: de Gruyter, 1968; Anmerkungen, Berlin/New York: de Gruyter, 1977. Tradução de Paulo Quintela. Lisboa: Edições 70, 1960.

. Kritik der praktischen Vernunft (KpV). Hrsg. von Karl Vorländer. Hamburg: Felix Meiner, 1993 (Philos. Bibliothek Bd. 38 a). Tradução de Valério Rohden. São Paulo: Martins Fontes, 2002.

. Briefwechsel (Br). In: Kants gesammelte Schriften, hrsg. von der Deuschen Akademie der Wissenschaften, Bde. X-XIII. Berlin und Leipzig: de Gruyter. 1928. Tradução de Arnulf Zweig. New York: Cambridge University Press, 1999.

PERIN, A. The canon of pure reason: Kant on the non-dependent establishment of the practical use and the unity of reason. Ethic@, v. 7, p. 137-150, 2008.

E-mail: adrianoperin@yahoo.com.br

Recebido: junho/2009

Aprovado: agosto/2009 